\title{
Research on the Urban Economic Structure of Liao Dynasty
}

\author{
Yusi $\mathrm{Lu}^{1, \mathrm{a}}$ \\ ${ }^{1}$ Urban Research Institute, School of History and Culture, Sichuan University, Chengdu, Sichuan \\ Province, China \\ ${ }^{a}$ stillspain@126.com
}

Keywords: Liao Dynasty; Urban Economy; Handicrafts; Commerce.

\begin{abstract}
Historically, a unified regime gave great impetus to the development of urban economy, while the prosperous urban economy promoted the development of the city in turn. After the Kihtan regime was stably established in the northern China, the civilizations of the nomad and the Central Plains experienced a great integration and exchange. Gradually, the social economy of Kihtan had been transformed from hunting-fishing economy to semi farming-husbandry economy. Meanwhile, with this transformation, urban handicrafts and commerce boomed rapidly. These turned out to be a historic factor that driving the urban economic development of Liao dynasty as well as the social changes.
\end{abstract}

\section{Introduction}

Liao dynasty (907-1125) was founded with the increasingly strengthen of Kihtan. Before forming the unified regime, Kihtan lived in the northern part of the Central Plains and had a nomadic life. As the natural conditions were weak and the social productivity level was low, the agriculture turned out to be less developed and the stable living way was unnecessary. In AD 907, the leader of Kihtan named Apaochi established the unified regime. Then, under the guidance of military expansion policy, Kihtan had successively occupied Bohai and You-Yun areas where the agriculture was much advanced than the cradle of Kihtan. Since each emperor of Liao had attached great importance to the development of agriculture production, the social economy of Kihtan had been transformed to semi farming-husbandry economy, which provided a solid material foundation for the development of urban economy. The structure of urban economy in Liao dynasty mainly covered urban handicrafts and urban commerce, and its prosperity partly owed to absorbing the advanced technology and civilization from the Central Plains. The progress of urban handicrafts and commerce did promote the establishment of the urban market system as well as accelerate the rapid development of the city in Liao dynasty.

\section{The Progress and Differentiation of the Urban Handicrafts}

During the period of Kihtan, handicrafts were mainly subordinated to the nomadic economy. After the unified Kihtan regime was stably established in the northern China, as the development of agriculture production and the expansion of farming civilization, handicrafts were gradually separated from the nomadic economy and became an independent production sector of urban economy. On the one hand, traditional handicrafts such as iron, harness manufacturing, ceramic and etc began to flourishing and making achievements in terms of both production technology and scale, which had a great significance to promote the progress of urban commodity economy. On the other hand, the Hans who under the leadership of Khitan regime did inject new vitality into the development of urban economy, which was mainly manifested on providing sufficient labor force and advanced manufacturing technology for the development of Khitan's handicrafts. Thus, new kinds of handicrafts had appeared and been developed well. For instance, new technology manufacturing like textile, salt-making, shipbuilding and etc had experienced a good development after the establishment of Liao dynasty. Originally, Khitan nomads were neither familiar with these new technologies nor good at manufacturing it. However, under the impacts of the integration of 
agricultural and nomadic civilization, they progressively had a good understanding of mastering these new handicrafts.

In general, since Khitan's handicrafts had been separated from the hunting and fishing economy, urban handicrafts of Liao dynasty had gave an impetus to the progress of urban economy as an independent production sector. In addition to the traditional handicrafts had been differentiated from the nomadic economy and continued to develop, new kinds of technology manufacturing had been promoted as well. Various kinds of handicrafts products were made to meet the needs of people's daily life instead of serving for the nomadic animal husbandry. To some extent, the enhancement and prosperity of urban handicrafts had greatly promoted the urban economic development of Liao dynasty as well as enriched the social life of all ethnic groups of people, particularly the nomads.

\section{The Prosperity of Urban Commerce}

Facilitated by the unification of political force, the urban economic function of Liao dynasty was increasingly strengthened. With the development and expansion of urban handicrafts, urban commerce of Liao developed rapidly that included both domestic and foreign trade.

Domestic Trade. In the agricultural era, as a vitally important force, the political function is the foremost determinant for the development of Chinese City. Thus, a large scale of markets was normally formed around the location of the administrative institution as a result of their regionally administrative center function. Due to the aggregation of settled populations in towns, urban commercial exchange was increasingly expanding for the sake of meeting the living and producing needs of urban residents. The 5 capital cities of Liao were the most important commercial trade centre considering with its highest administrative level and greatest population all over the country. As the political, economic, and cultural center in the early Liao dynasty, Shangjing was the most important regional market which was not only the gathering place of envoys and trading groups in the case of the Central Plain and other countries, but also was the commercial center and materials collective place of the whole empire. Its commercial district was located in the northern part of the city, and in the market, people used cloth to barter with each other. This common phenomenon means that the development level of commodity economy was still low in the early Liao dynasty. In the late Liao, Zhongjing City, which was constructed by imitating the capital of Northern Song, tended to be another importantly regional market on the northern grass plain. According to historical records, even though the residential and the commercial areas were separate in Zhongjing, the trading activities were not merely conducted at the commercial area. Shops were set up along the street. It means that the commercial activities of Zhongjing had broken the restrict boundary between the living area and business area. As a result, on the local Khitan's grassland, a regional market had been formed which was composed of Shangjing, Zhongjing City and the towns around them. Dongjing City was another importantly regional commercial center of Liao dynasty. The market of Dongjing City was divided into southern market and northern market. Moreover, it is important to note that the market of Dongjing City was not only composed of two parts, but also had two trading periods: the morning market and the evening market. Unsurprisingly, the commercial development of Dongjing at that time was prosperous. Xijin Prefecture of Nanjing was the most developed regional market in Liao dynasty. Originally, it was an important town, named Youzhou, in Tang dynasty. Since the You-Yun areas were incorporated into Liao dynasty, the identity of the capital city had been established that could further strengthen the position and role of its economic center. Within over 300 thousand families in this magnificent city, Nanjing became an obvious economical metropolis and had markets with thousands of products.

Under the impact of the core regional commercial developing, general towns set market up around the capital cities in Liao dynasty. Some general towns, where transactions were made periodically, were still in the primitive form and its development level was equivalent to the rural areas. Because the development of town markets was extremely relied on cities, fixity was its obvious feature. Therefore, the 5 capital cities and these general markets with different scales had constituted a national commercial network in Liao dynasty. 
Foreign Trade. In addition to the domestic trade, foreign trade of Liao had been developed as well. The border market system of Liao dynasty was built since Liao had traded with its neighboring countries and vassal countries. Thus, the specific border market system was formed on the boundary. Trading with the Northern Song was the main part of Liao's foreign commerce. According to the record of History of Jin Dynasty, "Que Chang", which was a market that was controlled by government, was the place where Liao dynasty made a long-term trading exchange with the Northern Song on its southern border. In the transactions, the goods of Liao were mostly raw material while the main outputs of Northern Song were handcrafts which had a higher technique. It indicates the fact that the nomads of the north had a relatively single economic structure in the ancient China. They needed to exchange products with agricultural region of the south. Therefore, the commercial exchanges strengthened the contact between the northern nomads and the southern people. Besides, trades with vassal states were made periodically as a result of the tribute relation between Liao and its vassal countries. Liao dynasty had 59 vassal countries, among those vassal countries, there were Xixia, Korea, and Gaochang and so on; and, most of these vassal countries maintained a stable trading relationship with Liao. In fact, this tribute relation was a commercial relation, contributing product and cultural exchange among them. Some of this kind of trades was conducted in the capital cities; however, most and primary of these trades were undertaken on the boundary. This mode is another part of specific border market which contributed a lot to the foreign trade of Khitan. As a result of their different trading types, the market of the border area in Liao dynasty also demonstrated the feature of diversity.

\section{Conclusion: The Feature of Urban Economic Structure in Liao Dynasty}

It should be noted that there were several economic structures that were observed in Liao dynasty. As Liao has a multiethnic society, and, these ethnicities are distinguished from each other by their economic development, production, and lifestyle. Their farming and animal husbandry are cross-correlated. Because of above phenomenon of Liao dynasty, the dominance hierarchy applied for distinguishing strategies to govern differently cultural ethnicities. This strategy ensures that each ethnicity enabled to maintain their cultures and work in their own way. Thus, as a result of the multiracial society, the distinguishing strategies had enhanced the diversity of the market, which supplied the place for trading. In fact, Market is a place in which buyer and seller make transactions, and the structure of market is defined as an organic combination that consists of various types of markets. Under the influence of the specifically historic period and social environment, the structure of urban market in Liao dynasty turned out to be an extremely complicated issue and had different features. For instance, comparing to the border market, which had an obvious characteristic of mobility, town's regional market demonstrated a relatively strong fixity and was also the market with the greatest scale and quantity of Liao dynasty. In addition, the prosperity of urban handicrafts and commerce were established on the basis of Khitan's weak social economy so that its overall level of development was far behind with respect to the Central Plains Dynasty like the Northern Song. However, peaceful coexistence and trading exchange among Liao and its neighboring countries did play an important role in enriching the resources of urban merchandises and promoting the progress of urban handicrafts and commerce. It can be said that the urban economic production of Liao was relatively rich in a certain degree.

To sum up, in Liao dynasty, China was facing the historical period of the second major split. The territory of Liao was across both Chinese ancient nomadic and farming regions. Because of Liao's specialized natural and geographical environment, the society, which was led by political power, demonstrated sort of diversification. The structure of urban economy also showed the diversified characteristics. It turned out to be that neither urban handicrafts nor commerce could be developed without the strong intervention of national political force. This characteristic was clearly emphasized in the trade market between Liao and Northern Song. In a word, in the process of its feudalization, the increasingly strengthened political force of Khitan was playing an important role in the development of urban economy. 


\section{References}

[1] Toqtaqu. History of Liao Dynasty[M], Zhonghua Book Company Press, 1974.

[2] Toqtaqu. History of Jin Dynasty[M], Zhonghua Book Company Press, 1975.

[3] Ye Longli. The History of Khitan State [M], Shanghai Ancient Book Publishing House, 1985.

[4] Si Maguang. Comprehensive Mirror for Aid in Government [M], Zhonghua Book Company Press, 1956.

[5] He Yimin. Development Priorities from the Political Center to the Economic Centre - the Transformation of the Dynamic Mechanism of Urban Development in China from the Agriculture Era to the Industrial Era[J], Journal of Southwest University for Nationalities. Humanities \& Social Sciences , 2004(01).

[6]Xiang Chunsong. History and Archaeology of Liao Dynasty [M], Inner Mongolia people's Publishing House, 1996.

[7] Wei Te-fu, Feng jiasheng. A Study of the Commerce in the Liao Dynasty[J]. Journal of Liaoning Normal University(Social Science Edition), 2005(02). 